\title{
PELATIHAN MENULIS CERITA DAN BERCERITA UNTUK MENINGKATKAN KOMPETENSI GURU PAUD DI KABUPATEN BOYOLALI JAWA TENGAH
}

\author{
Oleh: \\ Febritesna Nuraini, Dewi Eko Wati dan Dwi Hastuti \\ E-mail: febritesna@gmail.com
}

\section{Ringkasan}

Salah satu permasalahan di Guru PAUD Kabupaten Boyolali Jawa Tengah adalah rendahnya guru dalam menggunakan metode bercerita di dalam kelas. Metode bercerita merupakan salah satu metode yang digunakan guru untuk mengembangkan aspek-aspek yang ada di dalam anak, seperti kognitif, bahasa, fisik motoric, moral dan agama,dan seni. Oleh karena itu metode bercerita merupakan salah satu kegitan yang dapat membantu anak berkembang. Kenyataan di lapangan belum semua guru mampu menggunakan metode berceita sebagai sarana dalam pembelajaran dengan alasan terlalu susah. Berdasarkkan pemaparan tersebut pemberdayaan ini difokuskan pada pelatihan menulis cerita dan bercerita untuk guru PAUD. Metode pelaksanaan program pemberdayaan Masyarakat meliputi: pendidikan masyarakat, difusi teknologi dan praktek langsung. Dampak dari kegiatan PPM ini adalah: 1) tercipta kesadaran masyarakat sasaran tentang pentingnya pendidikan anak usia dini, 2) peningkatan pengetahuan masyarakat dalam mengolah program anak usia dini, 3) masyarakat terampil membuat karya kreatif

Kata kunci: Menulis Cerita, Bercerita Dan Guru

\begin{abstract}
One of the problems in PAUD teachers in Boyolali District of Central Java is the low level of teachers in using story telling methods in the classroom. The storytelling method is one of the methods teachers use to develop aspects that exist in children, such as cognitive, language, motor, moral and religious, and art. Therefore the story telling method is one of the activities that can help children develop. The reality in the field not all teachers are able to use the method berceita as a means of learning for reasons too difficult. Based on the exposure, this empowerment is focused on writing story training and storytelling for PAUD teachers. Methods of implementing the Community empowerment program include: community education, technological diffusion and direct practice. The impacts of these PPM activities are: 1) creating awareness of target communities on the importance of early childhood education, 2) increasing knowledge of the community in processing early childhood programs, 3) skilled people making creative work Keywords: Writing Stories, Storytelling And Teachers
\end{abstract}

\section{A. PENDAHULUAN}

Berkomunikasi menggunakan bahasa merupakan alat yang penting bagi setiap orang tak terkecuali anak usia dini. Melalui berbahasa seseorang atau anak akan dapat mengembangkan kemampuan bergaul (social skill) dengan orang lain. Penguasaan keterampilan bergaul dalam lingkungan sosial dimulai dengan penguasaan kemampuan berbahasa. Tanpa bahasa seseorang tidak akan dapat berkomunikasi dengan orang lain. Anak dapat mengekspresikan pikirannya menggunakan bahasa sehingga orang lain dapat menangkap apa yang dipikirkan oleh anak. Komunikasi antaranak dapat terjalin dengan baik dengan bahasa sehingga anak dapat membangun hubungan sehingga tidak mengherankan bahwa bahasa dianggap sebagai salah satu indikator kesuksesan seorang anak. Anak yang dianggap banyak berbicara, kadang merupakan cerminan anak yang 
cerdas. Perkembangan bahasa pada anak usia dini sangat penting karena dengan bahasa sebagai dasar kemampuan seorang anak akan dapat meningkatkan kemampuan kemampuan yang lain. Pendidik perlu menerapkan ide - ide yang dimilikinya untuk mengembangkan kemampuan berbahasa anak, memberikan contoh penggunaan bahasa dengan benar, menstimulasi perkembangan bahasa anak dengan berkomunikasi secara aktif. Anak terus perlu dilatih untu k berpikir dan menyelesaikan masalah melalui bahasa yang dimilikinya. Kegiatan nyata yang diperkuat dengan komunikasi akan terus meningkatkan kemampuan bahasa anak. Lebih daripada itu, anak harus ditempatkan di posisi yang terutama, sebagai pusat pembelajaran yang perlu dikembangkan potensinya. Anak belajar bahasa perlu menggunakan berbagai metode dan strategi misalnya

dengan permainan - permainan dan cerita yang bertujuan mengembangkan bahasa anak. dan penggunaan media pembelajaran sebagai sarana.

Pengenalan ataupun pembelajaran bahasa termasuk bahasa Indonesia merupakan pelajaranyang ada pada tiap jenjang pendidikan, dari prasekolah hingga perguruan tinggi. Khusus pengenalan bahasa untuk anak usia dini perlu mendapat perhatian khusus karena usia dini merupakan usia emas untuk pengembangan segala bidang termasuk bahasa. Untuk itu, guru PAUD perlu memiliki keterampilan dan kreativitas dalam menggunakan metode pembelajaran bahasa untuk anak usia dini. Mendongeng dan bercerita merupakan metode pembelajaran yang sampai saat ini masih disukai oleh anak-anak, lebih-lebih anak usia PAUD. Dengan mendongeng dan bercerita guru dapat berkomunikasi dengan baik kepada siswanya untuk menyampaikan pesan pendidikan dengan mudah. Dengan demikian, mendongeng dan bercerita dapat dijadikan metode pengenalan yang baik dalam menyampaikan materi bahasa pada anak usia dini.

Berdasarkan hasil pengamatan dan wawancara terdapat $80 \%$ guru-guru yang belum mampu mengusai metode tersebut. Berangkat dari permasalahan itulah maka dianggap mendesak untuk membekali guru-guru PAUD. Guru PAUD Melalui guru- guru PAUD dan TK itulah pembelajaran bahasa nantinya dapat disampaikan dengan metode yang tepat dan menyenangkan sehingga sejak dini para siswa sudah mulai senang dengan pembelajaran bahasa. Dengan senang belajar bahasa maka untuk memahami pembelajaran yang lain akan lebih mudah. Menjadiguru apalagi guru PAUD dan TKmemang tidak semudah yang dibayangkan. Banyak tugas yang harus diselesaikan. Sementara untuk mencapai hasil belajar yang maksimal perlu upaya yang keras, kecakapan teori, dan praktiknya. Semuanya harus seimbang dan diselaraskan dengan tujuan yang hendak dicapai. Guru PAUD dan TK bukannya tidak mau untuk menjadi lebih baik dan produktif. Hanya saja perlu ajang bersama untuk saling memotivasi dan menyegarkan kembali materi yang dapat memacu mereka untuk mulai berkarya. Salah satu cara yang dapat dilakukan adalah dengan pelatihan. Pelatihan pengembangan metode pengenalan atau pembelajaran ini diajukan dengan pertimbangan bahwa guru - guru PAUD dan TK membutuhkan sarana pertemuan akademik yang merangsang mereka untuk mau berkarya. Kegiatan ini akan menjadi rangasangan inovatif agar para guru dapat saling berinteraksi dan brainstorming. 
Diterbitkan oleh Lembaga Pengabdian kepada Masyarakat

Universitas Ahmad Dahlan Yogyakarta

\section{B. METODE PELAKSANAAN}

Untuk mencapai tujuan yang diharapkan, program PPM di Guru PAUD Kabupaten Boyolali dilaksanakan dengan pemberdayaan masyarakat melalui pendidikan dan pelatihan masyarakat, difusi ilmu pengetahuan dan teknologi dan praktek langsung. Ringkasan metode pelaksanaan beserta jam kerja efektif mahasiswa (JKEM) tersaji pada table I.

Tabel I. Metode, Kegiatan, JKEM dan keterlibatan mahasiswa

\begin{tabular}{|l|l|l|l|l|}
\hline No & Metode & Kegiatan & JKEM & $\begin{array}{l}\text { Jumlah dosen dan } \\
\text { mahasiswa yang } \\
\text { terlibat }\end{array}$ \\
\hline 1 & $\begin{array}{l}\text { Pendidikan } \\
\text { masyarakat }\end{array}$ & $\begin{array}{l}\text { Menyelenggarakan } \\
\text { penyuluhan } \\
\text { penting } \\
\text { Pendidikan nya } \\
\text { Anak Usia Dini }\end{array}$ & $10 \times 2$ jam & 1 dan 2 mahasiswa \\
\hline 2 & Difusi iptek & $\begin{array}{l}\text { Menyelenggarakan } \\
\text { pelatihan } \\
\text { pembuatan cerita } \\
\text { dan bercerita }\end{array}$ & $10 \times 2$ jam & 1 dan 2 Mahasiswa \\
\hline 3 & Praktek & $\begin{array}{l}\text { Pelatihan } \\
\text { pembuatan boneka } \\
\text { dari botol plastic } \\
\text { bekas }\end{array}$ & $4 \times 2$ jam & 3 mahasiswa \\
\cline { 2 - 5 } & $\begin{array}{l}\text { Pelatihan } \\
\text { pembutan bangun } \\
\text { ruang }\end{array}$ & $\begin{array}{l}\text { Pengadaan } \\
\text { kebun }\end{array}$ & 9 jam & 9 \\
\hline & & 9 jam & 9 \\
\hline
\end{tabular}

\section{HASIL dan PEMBAHASAN}

\section{Profil Guru}

Guru PAUD di kabupaten Boyolali Jawatengah dari 60 peserta mengikuti pelatihan mayoritas belatar belakang pendidkan SMA/ sedrajat dan hanya 5 guru yang sedang menempuh S1 PGPAUD di UT.

\section{Gambaran pelaksanaan}

Kegiatan pembardayaan masyarakat Dusun gedad di laksanakan dalam suatau sistematika program kerja yang legal dan baku dengan keterlibatan berbagai pihak. Kegiatan pelaksanaan program tidak lepas dari swadaya masyarakat yang sangat 
membantu keberhasilan program. Hal ini ditunjukan dari hasil observasi masyarakat saat dilksanakan pelatihan dan penyuluhan, dari peserta yang di undang kurang lebih $70 \%$ hadir.

Keberhasilan sebuah pelatihan tidak lepas dari pran masyarakat dalam mengembangkan potensi yang ada di daerah. Peningkatan sebuah ilmu di masyarakat pada dasarnya bertujuan untuk menembangkan kualitas sebuah program, agar kader SPS PAUD mampu menciptakan kondisi pembelajaran yang memungkinkan berdasar dari hasil pelatihan.

Pelatihan yang dikembangkan di wilayah tersebut tidak lepas dari memanfaatkan potensi desa yang ada. Karena memanfaatkan potensi desa menghasilkan dampak yang positif bagi masyarakt, salah satu nya adalah mengenalkan pengelolaan lingkungan dengan menanam tanman sehat atau kebun gizi.

\section{KESIMPULAN}

Program kegiatan PPM UAD dalam pelatihan menulis cerita dan bercerita untuk meningkatkan kompentensi guru PAUD berjalan dengan baik. 